\title{
Elective open bedside tracheostomy in the neurosurgical intensive care unit
}

\author{
Niran Maharjan ${ }^{1}$, Sangeeta Shrestha ${ }^{2}$, Binod Bhattarai ${ }^{3}$, Iype Cherian ${ }^{4}$ \\ ${ }^{1}$ Resident, Department of Surgery, COMS-TH, Bharatpur, Nepal \\ ${ }^{2}$ Asst. Prof, Department of Anesthesia, Maternity hospital, Kathmandu, Nepal \\ ${ }^{3}$ Asst. Prof., ${ }^{4}$ Prof. and HOD, Dept. of Neurosurgery, COMS-TH, Bharatpur, Nepal
}

Correspondence
Dr. Niran Maharjan
Department of Surgery,
COMS-TH,
Bharatpur, Nepal
Email:
drniranmaharjan@gmail.com
DOI: http://dx.doi.org/10.3126/
jcmsn.v11i1.13315

jemsn.v11i1.13315

\begin{abstract}
Background and Objectives: Tracheostomy is electively performed in critically ill patients requiring prolonged respiratory support. The risk of transporting, the increasing associated cost and operative room schedule are some of the obstacles for wider acceptance of this procedure. The use of rigid selection criteria exclude many patients who would benefit of this approach. The present study was designed to determine the safety of open bedside tracheostomy (OBT) as a routine intensive care units (ICU) procedure without any selection criteria, considering its peri and postoperative complications. Materials \& Methods: Retrospective medical chart review of all patients that underwent elective tracheostomy between June 2014 and January 2015. Results: The study group comprised 52 patients with a mean age of $40.4 \pm 15.1$ years. The incidence of intraprocedure complications was $5.7 \%$ and post-procedure complications was 3.8\%. Conclusions: Open bedside tracheostomy seems to be a safe and simple procedure, even when performed by a trained resident under controlled circumstances, and should be considered as an option for ICU patients.
\end{abstract}

Key words: Complications, Intensive care units, Tracheostomy

Citation: Maharjan N, Shrestha S, Bhattarai B, Cherian I . Elective open bedside tracheostomy in the neurosurgical intensive care unit. JCMS Nepal. 2015;11(1):9-11.

\section{INTRODUCTION}

Securing the airway by way of a tracheostomy had been reported back to ancient times. The procedure was popularized in the early 1900 s by Chevalier Jackson and is currently used in intensive care units (ICU) across the world. ${ }^{1}$ Tracheostomy is electively performed in critically ill patients requiring prolonged respiratory support or frequent bronchopulmonary toileting, or to help with weaning from mechanical ventilation. It is better tolerated than oral or nasal tracheal intubation and is thought to reduce sedation requirements and time in the intensive care unit (ICU). ${ }^{2-6}$

The concept of bedside tracheostomy is attractive, and surgeons have started performing open bedside tracheostomies (OBT). This approach has proved to be safe in selected patients. ${ }^{7-10}$ In a prospective randomized study, Massicket al ${ }^{10}$ found excellent results and stated that OBT represents the standard of care in bedside tracheostomy, since it provides a more secure airway at markedly reduced patient charge. The primary objective of this study was to determine the safety of OBT as a routine ICU procedure without any selection criteria, considering its peri- and postoperative complications.

\section{MATERIALS AND METHODS}

The neurosurgical ICU of the college of medical sciences and teaching hospital (COMS-TH), Bharatpur, Nepal had an established bedside tracheostomy protocol. A retrospective medical chart review was conducted including all 52 intubated patients who underwent elective ICU tracheostomies between June 2014 and January 2015. Indications and timing were decided by the neurosurgical team. This study was approved by the Institutional Ethical Committees; informed consent was taken. No selection criteria at all were adopted. All operations were performed by trained neurosurgical residents assisted by either another resident or ICU nurse who were previously trained and knew all necessary materials and surgical steps. Coagulation disturbances, if present were appropriately corrected to permit the surgical approach. Hemodynamic parameters and oxygen saturation were monitored constantly throughout the procedure. A trained ICU nurse was always present to insure respiratory care and to help with extubation. 
The technique used was that standardized at the facility. The patients were sedated with intravenous midazolam and maintained in the horizontal supine position. A pad was placed under the scapular region for neck extension. After antisepsis, sterilized cloths were placed on site, and a solution of $2 \%$ lidocaine was used for local anesthesia. A 3 $\mathrm{cm}$ horizontal skin inci-sion was made, and the muscles were split longitudinally until the tracheal rings could be seen. The opening in the trachea was made, using a scalpel, in a "U" shape, and the cuffed tracheostomy tube of sizes varied from 6.5 to 7.5 was inserted through the tracheal opening immediately after the orotracheal tube was removed. The correct positioning of the tube was always confirmed by inserting an aspira-tion tube prior to connecting it to the mechanical ventilator, after which the tracheal tube was fixed.

Chest radiography was obtained the next day following the ICU routine to confirm appropriate tracheostomy placement and evaluate for pneumothorax. Complications of OBT were recorded up to 30 days after the procedure. Complications were defined as follows: failure to perform the procedure in the ICU, bleeding, subcutaneous emphysema, pneumothorax, pneumomediastinum, false passage during the insertion of the tube, fistula, and infection at the incision site. Stomal or endotracheal bleeding related to the procedure was considered significant (major) only if operative room (OR) exploration and/or blood transfusion was required. Bleeding was considered minor when controlled by digital compression, surgical tie or gauze packing in the ICU. Stomal infection was diagnosed when cellulitis around the stoma was present. Cost estimation for the open bedside procedure was estimated by including procedure charge, materials, drugs, and OR taxes when applicable.

\section{RESULT}

All the 52 patients admitted in the neurosurgical ICU who underwent tracheostomy werepost operative cases with the endotracheal tube in situ. $33(63.5 \%)$ of them were in T-tube support who required prolong respiratory support or frequent bronchopulmonary toileting and $19(36.5 \%)$ of them were the one with difficulty in weaning from mechanical ventilation. All the tracheostomies were performed between $4^{\text {th }}$ to $7^{\text {th }}$ day of intubation (mean: 4.71 days).

The age of the 52 patients ranged from 15 to 70 years (Mean: 40.42 years). Out of the 52 patients, $34(65.4 \%)$ were male and 18 were female. The mean operation time was 28.63 minutes (range: 16 to 65 minutes).

Early complications during the procedure occurred in $3(5.7 \%)$ patients and late complications occurred in $2(3.8 \%)$ patients, as summarized in Table 1.

Table 1: Complications of open bedside tracheostomy

\begin{tabular}{lll}
\hline Parameters & $\mathbf{n}$ & $\mathbf{\%}$ \\
\hline Intra-procedure complications & & \\
Minor bleeding & 2 & 3.8 \\
False tract & 1 & 1.9 \\
Post-procedure complications & & \\
Subcutaneous emphysema & 1 & 1.9 \\
Stomal infection & 1 & 1.9
\end{tabular}

The cause of the minor bleeding was the presence of aberrant vessels and both were managed in ICU by tying with the suture. A false tract was created during the procedure on a 48 years old obese gentleman who had a short neck and he developed subcutaneous emphysema localized to the neck which spontaneously disappeared after 6 days. Stomal infection was diagnosed in one patient by the presence of cellulitis around the stoma and was managed with daily dressing.

There were no procedure-related deaths, although 6 (11.5\%) patients died of severe head injury. The mean cost for the procedure was NRs 1175.3 (range: 1100 to $1215 \mathrm{NRs}$ ), excluding the operation charge of NRs 3000 that was made free for every case.

\section{DISCUSSION}

When performed early, tracheostomy reduces the time on mechanical ventilation, the length of ICU stay, and the incidence of bronchopneumonia, ${ }^{11,12}$ as well as minimizing laryngeal trauma. ${ }^{13}$ Some authors ${ }^{12}$ have reported a procedure-related morbidity of $4 \%$, whereas others ${ }^{7}$ have reported that tracheostomy-related morbidity is $9.4 \%$ in the operating room and $8.7 \%$ in the ICU.

Though the tracheostomy literature offers a diverse opinion concerning contraindications to bedside performance, the safety of bedside tracheostomy has been established. ${ }^{7-9,14}$ Other authors have also suggested performing the procedure in the ICU as a safe and accept-ably cost-effective alternative. ${ }^{15-17}$

Owing to the lack of available data concerning complications of tracheostomy performed in the operating room, it is difficult to make direct comparisons between our complication rate and those of tracheostomy performed in the operating room. However, our complication rates of $5.7 \%$ for major complications and $3.8 \%$ for minor complications are similar to many quoted in the 


\section{literature..$^{7,17}$}

There is great concern regarding the possibility of severe infections, since the procedure would not be performed in an appropriate environment. This was not identified in the present study either. The one case of infection (1.9\%), which occurred surrounding the tube and were treated by applying local dressings, were listed as procedure-related complications. However, we had difficulty in determining whether they were related to the technique used and the place where the procedure was performed or were the result of the tracheal infection occurring in these patients who had spent a long period in the ICU.

\section{CONCLUSION}

The absence of procedure-related mortality and the possibility of successfully performing all the interventions in the ICU, even when they are performed by surgeons in training under the supervision of a specialist, show that the difficulties related to the place where the procedure was performed were not significant. We believe that performing tracheostomy in the ICU, as long as the complication rate is comparable to that of tracheostomy performed in the oper-ating room, can have advantages, since it prevents patients connected to multiple devices from being moved. We conclude that tracheostomy in the ICU is feasible and presents a low rate of complications, even when performed in critically ill patients and by a trained resident. Therefore, in our view, it is possible to state that performing tracheostomy in the ICU is worthwhile.

\section{REFERENCES}

1. Higgins KM, Punthakee X. Meta-analysis comparison of open versus percutaneous tracheostomy. Laryngoscope. 2007;117:447-54. DOI:10.1097/01.mlg.0000251585.31778.c9. PMID: 17334304.

2. Freeman BD, Isabella K, Cobb JP, Boyle WA, Schmieg RE $\mathrm{Jr}$, Kolleff $\mathrm{MH}$, et al. A prospective, randomized study comparing percutaneous with surgical tracheostomy in critically ill patients. Crit Care Med. 2001;29:926-30. DOI:10.1097/00003246-200105000-00002. PMID:11378598.

3. Bowen CP, Whitney LR, Truwit JD, Durbin CG, Moore MM. Comparison of safety and cost of percutaneous versus surgical tracheostomy. Am Surg. 2001;67:54-60. PMID:11206898.

4. Grover A, Robbins J, Bendick P, Gibson M, Villalba M. Open versus percutaneous dilatational tracheostomy: efficacy and cost analysis. Am Surg. 2001;67:297-301. PMID:11307993.

5. Fikkers BG, Fransen GA, van der Hoeven JG, Briedé IS, van den Hoogen FJ. Tracheostomy for long-term ventilated patients: a postal survey of ICU practice in The Netherlands. Intensive Care Med. 2003;29:1390-3. DOI:10.1007/s00134- 003-1824-x. PMID:12879247.

6. Bacchetta MD, Girardi LN, Southard EJ, Mack CA, Ko $\mathrm{W}$, Tortolani AJ, et al. Comparison of open versus bedside percutaneous dilatational tracheostomy in the cardiothoracic surgical patient: outcomes and financial analysis. Ann Thorac Surg. 2005;79:1879-85. DOI:10.1016/j.athoracsur.2004.10.042. PMID:15919277.

7. Upadhyay A, Maurer J, Turner J, Tiszenkel H, Rosengart T. Elective bedside tracheostomy in the intensive care unit. J Am Coll Surg. 1996;183:51-5. PMID:8673307.

8. Wease GL, Frikker M, Villalba M, Glover J. Bedside tracheostomy in the intensive care unit. Arch Surg. 1996;131:552-5. archsurg.1996.01430170098018. PMID:8624204.

9. Wang SJ, Sercarz JA, Blackwell KE, Aghamohammadi M, Wang MB. Open bedside tracheostomy in the intensive care unit. Laryngoscope. 1999;109:891-3. DOI:10.1097/00005537199906000-00009. PMID:10369277.

10. Massick DD, Yao S, Powell DM, Griesen D, Hobgood $\mathrm{T}$, Allen JN, et al. Bedside tracheostomy in the intensive care unit: A prospective randomized trial comparing open surgical tracheostomy with endoscopically guided percutaneous dilational tracheostomy. Laryngoscope. 2001;111:494-500. DOI:10.1097/00005537-200103000-00021. PMID:11224782.

11. Rodriguez JL, Steinberg SM, Luchetti FA, Gibbons KJ, Taheri PA, Flint LM. Early tracheostomy for primary airway management in the surgical critical care setting. Surgery. 1990;108:655-9. DOI:10.1002/bjs.1800771228.

12. Fradis M, Malatskey S, Dor I, Krimerman S, Joachims HZ, Ridder GJ, Golz A. Early complications of tracheostomy performed in the operating room. J Otolaryngol. 2003;32:55-7. DOI:10.2310/7070.2003.35310. PMID:12779263.

13. Zeitouni AG, Kost KM. Tracheostomy: a retrospective review of 281 cases. J Otolaryngol. 1994;23:61-6. PMID:8170024.

14. Futran ND, Dutcher PO, Roberts JK. The safety and efficacy of bedside tracheostomy. Otolaryngol Head Neck Surg. 1993;114:707-11.

15. Hawkins ML, Burrus EP, Treat RC, Mansberger AR Jr. Tracheostomy in the intensive care unit: a safe alternative to the operating room. South Med J. 1989;82:1096-8.DOI: 10.1097/00007611-198909000-00009. PMID:2641208.

16. Stevens DJ, Howard DJ. Tracheostomy service for ITU patients. Ann R Coll Surg Engl. 1988;70:241-2. PMID:3415173. PMCID:PMC2498772.

17. François B, Clavel M, Desachy A, Puyraud S, Roustan J, Vignon P. Complications of tracheostomy performed in the ICU: subthyroid tracheostomy vs surgical cricothyroidotomy. Chest. 2003;123:151-8. DOI:10.1378/chest.123.1.151. PMID: 12527616 